\title{
The role of nitric oxide in the transformation of visual information within the dorsal lateral geniculate nucleus of the cat
}

\author{
J. Cudeiro, K.L. Grieve, C. Rivadulla, R. Rodríguez, S. Martínez-Conde, C. Acuña
}

\begin{abstract}
We have shown that application of an inhibitor of the enzyme nitric oxide synthase (NOS) effectively suppresses the visual responses of relay cells in the dorsal lateral geniculate nucleus (dLGN) of the anaesthetized paralysed cat. Such suppression seems to result from a specific reduction in transmission via $N$ - methy $1-d-$ aspartic acid (NMDA) receptors, since iontophoretic application of the inhibitor of NOS selectively and in a dose-dependent manner decreased the responses to exogenously applied NMDA. Responses to other exogenously applied amino acid agonists, such as quisqualate (Quis), kainate (Kain) and $\alpha$-amino-3-hydroxy-5-5-methyl-4-isoxazole-propionic acid (AMPA) were largely unaffected. Furthermore, the excitatory action of acetylcholine (ACh), normally co-localized with NOS in axonal terminals within the dLGN arising from the brainstem, was also unaffected. Unlike some other actions of nitric oxide (NO), this role seems not to involve an increase in production of cyclic guanosine-3',5'-monophosphate (cGMP), since application of the membrane permeable cGMP analogue 8-bromo-cGMP did not alter the suppressive effect of NOS inhibitors on either visual or NMDA evoked responses. We conclude that the normal function of $\mathrm{NO}$ at this level of the visual system is permissive, allowing full expression of NMDA mediated visually elicited information.
\end{abstract}

Keywords: Nitric oxide; NMDA; visual system; cat; dorsal lateral geniculate nucleus (dLGN); nitric oxide synthase

Nitric oxide (NO) is a highly diffusible gaseous compound formed by the calcium dependent action of the enzyme nitric oxide synthase (NOS) on the amino acid L-arginine (L-Arg) (for a review see Garthwaite, 1991; Snyder and Bredt, 1991; Moncada et al., 1991). This compound is now widely regarded as a transmitter substance within the mammalian CNS, where its mode of action has previously been suggested to be retrograde, i.e. formed in post-synaptic cells, but diffusing to work upon presynaptic elements, probably by increasing levels of cyclic guanosine-3',5'-mono-phosphate (cGMP) (Garthwaite et al., 1988, 1989; Bredt and Snyder, 1989). Until now, a role in long-term potentiation (LTP) (Bohme et al., 1991; Haley et al., 1992; Schuman and Madison, 1991; Izumi et al., 1992) and long-term depression (LTD) (Shibuki and Okada, 1991) or a role in neurotoxicity/neuroprotective mechanisms (Dawson et al., 1991, 1993; Lei et al., 1992; Lipton et al., 1993) have been the favoured hypotheses, each involving a modulation of excitatory amino acid neurotransmission. Our most recent evidence, however, offers an alternative mechanism of action, at least within the dorsal lateral geniculate nucleus (dLGN) of the cat, a primary sensory nucleus within the visual system. In this nucleus incoming visual information from the retina is modified by both visual and non-visual inputs, en route to the visual cortex. It has been shown that visual input is heavily dependent upon N-methyl-D-aspartic acid (NMDA) mediated excitation (Kemp and Sillito, 1982; Sillito et al., 1990). At this site, NO is formed only in presynaptic elements, in axonal terminals of the cholinergic input from the brainstem (Bickford et al., 1993). Traditionally this input ,has been thought to be part of the system of arousal, enhancing the signalto-noise ratio of the visual information passing to the cortex (Singer, 1977; Sherman and Koch, 1986). The role of NO in this pathway seems to be crucial, since we have shown that the visual responses of dLGN cells are essentially dependent upon the production of $\mathrm{NO}$ at this level. Application of inhibitors of NOS to dLGN cells markedly suppresses all visual responses (Cudeiro et al., 1994a), and this role for NO involves the activation of NMDA receptors on the post-synaptic cell (Cudeiro et al., 1994b). Here we expand our hypothesis to examine the selectivity of this action, and address some possible mechanisms. 


\section{Methods}

Experiments were carried out on 15 adult cats anaesthetized with a mixture of $\mathrm{N}_{2} \mathrm{O}(70 \%) 0_{2}(30 \%)$ and halothane (0.1-5\%). The level of halothane was varied as necessary over the course of the experiment with $5 \%$ at the induction of anaesthesia, 2-4\% during surgical procedures, and a subsequent long-term maintenance level of $0.1-0.5 \%$ after paralysis with gallamine triethiodide $(40 \mathrm{mg}$ initial dose, then 10 $\mathrm{mg} / \mathrm{kg} / \mathrm{hr}$ ). End-tidal $\mathrm{CO}_{2}$ levels, ECG waveform, intersystolic interval and the frequency of spindles in the EEG were monitored continuously through the experiment. The rate and depth of artificial ventilation was adjusted to maintain end-tidal $\mathrm{CO}_{2}$ at 3.8-4.2\%; the level of halothane was chosen to give a state of light anaesthesia. Once a stable state was reached, any variation in the monitored parameters commensurate with a change in the depth of anaesthesia was immediately compensated for by adjusting the level of halothane. All wounds margins were treated with s.c. injections of procaine hydrochloride, and the ear bars of the stereotaxic apparatus were coated with antiseptic lignocaine hydrochloride gel. The eyes were treated with atropine methonitrate and phenylephrine hydrochloride and protected with plastic contact lenses.

Seven barrelled micropipettes were used for recording single-unit activity and the iontophoretic application of drugs. Each drug barrel of the electrode contained a selection of the following: $3 \mathrm{M} \mathrm{NaCl}$ for extracellular recording, $\mathrm{L}-\mathrm{Arg}(10 \mathrm{mM}, \mathrm{pH} 6.0)$, physiological substrate for NOS; $\mathrm{N}^{\mathrm{G}}$-nitro-L-arginine (L-NOArg, $10 \mathrm{mM}, \mathrm{pH}$ 6.0) a competitive inhibitor of NOS; quisqualate (quis, $25 \mathrm{mM}, \mathrm{pH} \mathrm{8.0);} \alpha$-amino3-hydroxy-5-5-methyl- 4-isoxazole-propionic acid (AMPA, $15 \mathrm{mM}, \mathrm{pH}$ 8); kainate (kain, $0.1 \mathrm{M}, \mathrm{pH} \mathrm{8}$ ); NMDA (0.1 M, pH 8); acetylcholine (ACh, $0.2 \mathrm{M}, \mathrm{pH} 4)$; 8-bromo-cGMP (10 mM, pH 4.5) and Pontamine sky blue ( $2 \% \mathrm{w} / \mathrm{v}$ in $0.5 \mathrm{M}$ sodium acetate) for histological reconstruction.

For each cell, after classification, visual responses were tested quantitatively before, during and after application of L-NOArg, alone or in combination with L-Arg. Visual stimuli, usually bars or gratings, were selected in order to engage different synaptic pathways, both from retina and visual cortex to dLGN, and to invoke visually elicited intrageniculate inhibitory mechanisms (for a review see Sillito, 1992). More details about visual stimulation and experimental procedures are given elsewhere (Sillito et al., 1993). Pulsatile application of excitatory amino acids were also quantitatively examined in the same manner.

\section{Results}

We have tested the effect of blockade of NO production on a population of $51 \mathrm{dLGN}$ cells. In terms of cell type, this population included $\mathrm{X}$ and $\mathrm{Y}$ cells of both ON and OFF subtypes, and therefore included representatives of all major relay cell types found in the A laminae of the cat dLGN. We observed no differences in the responses outlined below between the various cell types encountered. Figure 1 illustrates the effect of blockade of NO production on the responses of an ON X cell, stimulated with moving light bars of different lengths, [thus effectively engaging both retinally and cortically driven synaptic mechanisms (see Sillito, 1992)]. It is clear that at all bar lengths, responses are markedly reduced by application of L-NOArg [Fig. 1(a)]. In Fig. 1(b), application of L-Arg is shown to be without effect when applied alone, but, in combination with L-NOArg [Fig. 1(c)] the inhibitory effects of L-NOArg are completely reversed. In 32 out of 34 cells visual responses were effectively decreased by application of LNOArg, with a mean reduction of $60 \%$ (f $8 \%$, SEM). Recovery from the effect of the NOS inhibitor routinely took between 8 and $15 \mathrm{~min}$, in keeping with the known dissociation kinetics of the enzyme (Klatt et al., 1994).

The effect of application of L-NOArg upon NMDA mediated excitation was similar to that on visual responses. This is shown in Fig. 2. In all cells tested, L-NOArg clearly inhibited the responses to application of NMDA, although it has been previously demonstrated that L-NOArg itself has no direct effect on NMDA receptors (Dawson et al., 1991). The effect of different application currents of L-NOArg upon NMDA mediated responses are shown in Fig. 2(a), where the mean responses of a population of 25 cells are illustrated. From this histogram, it is obvious that L-NOArg decreased the dLGN cell responses in a dose-dependent manner. Figure 2(b) shows the responses of an ON Y cell to a range of application currents of NMDA (solid line). Application of L-NOArg (dashed line) almost completely suppressed the excitatory responses, an effect which was reversed by concurrent application of L-Arg (dot-dashed line), suggesting competitive inhibition of NOS. L-Arg applied alone had no effect on visual evoked responses (dotted line).

The selectivity of these suppressive effects is shown in Fig. 3. In this histogram, the responses of some 12 cells to a range of excitatory compounds are compared (solid bars). Application of L-NOArg (hatched bars) effectively and selectively reduced the responses to NMDA. Responses to the other amino acids, quis, AMPA and kain although affected were much less reduced, but did not reflect the action of a 
non-specific excitatory amino acid inhibitor since the responses to the non-amino-acid excitant ACh were equally, but marginally. affected. In fact, the inset to the figure reveals that there was a degree of nonspecific suppression of background activity, which can clearly account for the small effects seen on quis, AMPA, kain and ACh.

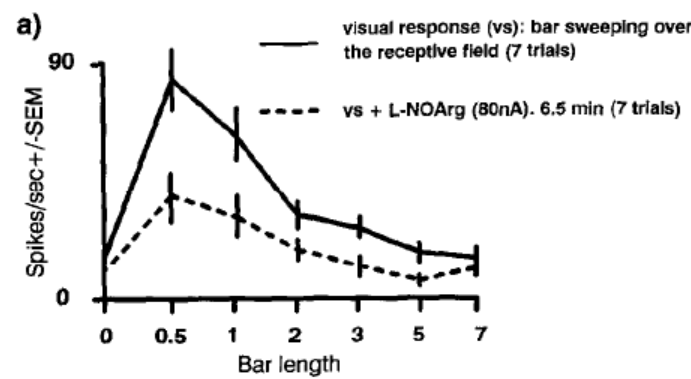

b)

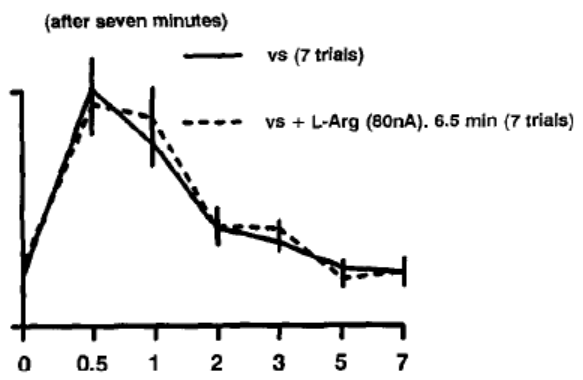

c)

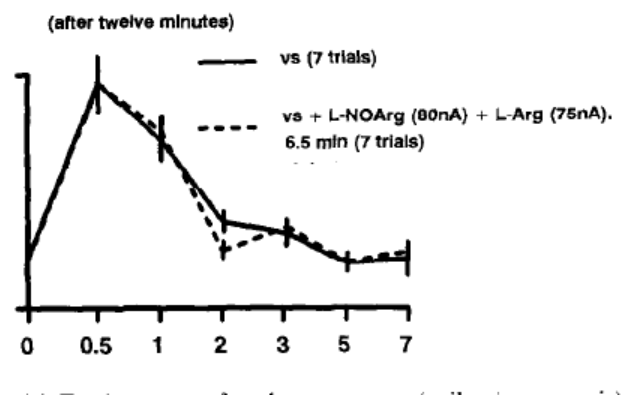

Fig. 1. (a) Tuning curve for the responses (spikes/set, $y$-axis) of an ON X dLGN cell to moving light bars of different length (degrees in length, $\mathrm{x}$-axis). Solid line represents the magnitude of control visual responses in the absence of pharmacological intervention. Dashed line gives the responses during continuous iontophoretic application of $80 \mathrm{nA}$ of L-NOArg. (b) The solid line represents the recovery of responses from drug application in (a), and the dashed line the subsequent set of responses measured during continuous application of $80 \mathrm{nA}$ of L-Arg. (c) Again the solid line represents recovery from the previous drug application and the dashed line the responses during continuous application of both L-NOArg and L-Arg, using application currents as above. Responses were measured in spikes/set \pm SEM during the visual response.

We have addressed one possible mechanism of action of this NMDA specific suppressive effect of NOS inhibition, and this is illustrated in Fig. 4. The histogram in Fig. 4(a) gives the mean responses of 10 cells, from left to right: to NMDA alone; NMDA in the presence of L-NOArg; in the presence of L$\mathrm{NOArg}+\mathrm{L}-\mathrm{Arg}$; and finally, in the presence of L-NOArg + 8-bromo-cGMP. Clearly, once more, L-Arg completely blocked the suppressive effects of L-NOArg, while 8-bromo-cGMP alone produced very small and variable effects (data not illustrated) and was unable to alter the effect of LNOArg. In Fig. 4(b), the comparable effects on visual responses are shown. The pattern of observed effects was remarkably similar-again L-NOArg suppressed visual responses, and was reversed by concurrent application of LArg, while application of 8-bromo-cGMP was unable to alter this suppression. This lack of an observable effect of 8-bromo-cGMP is in keeping with other published work (Tanaka et al., 1993). 
a)

NMDA ejection current $=90 \mathrm{nA}$

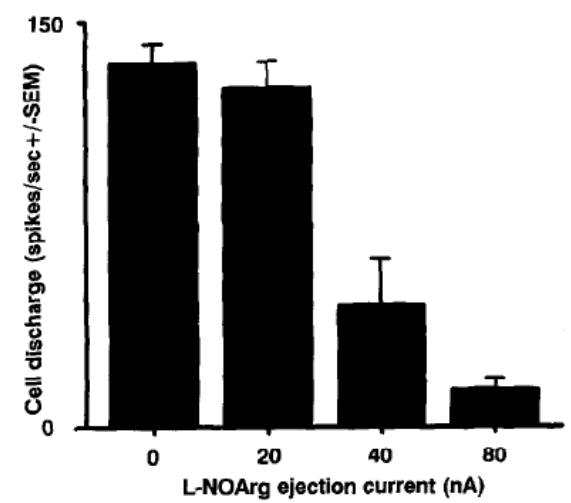

b)

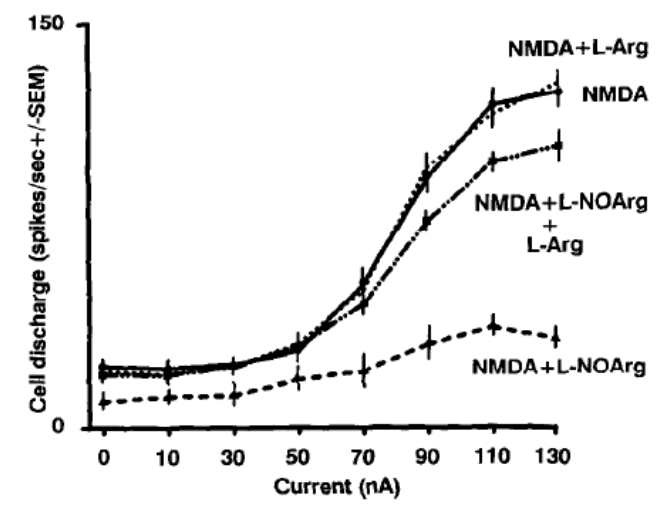

Fig. 2. (a) Histogram comparing the responses of a population of $25 \mathrm{dLGN}$ cells to pulsatile iontophoretic application of NMDA (90 $\mathrm{nA})$, in the absence of (0 nA) and during continuous application of 20,40 and $80 \mathrm{nA} \mathrm{L-NOArg}$ (left to right). Responses are given as mean \pm SEM, pulse length $3 \mathrm{sec}$. (b) Dose-response curves for an ON Y cell to incremental doses of NMDA in the range 0-130 $\mathrm{nA}$, alone (solid line), in the presence of L-NOArg (80 nA, dashed line), L-Arg (80 nA, dotted line) and both L-NOArg and L-Arg (80 nA each, dot-dashed line). 

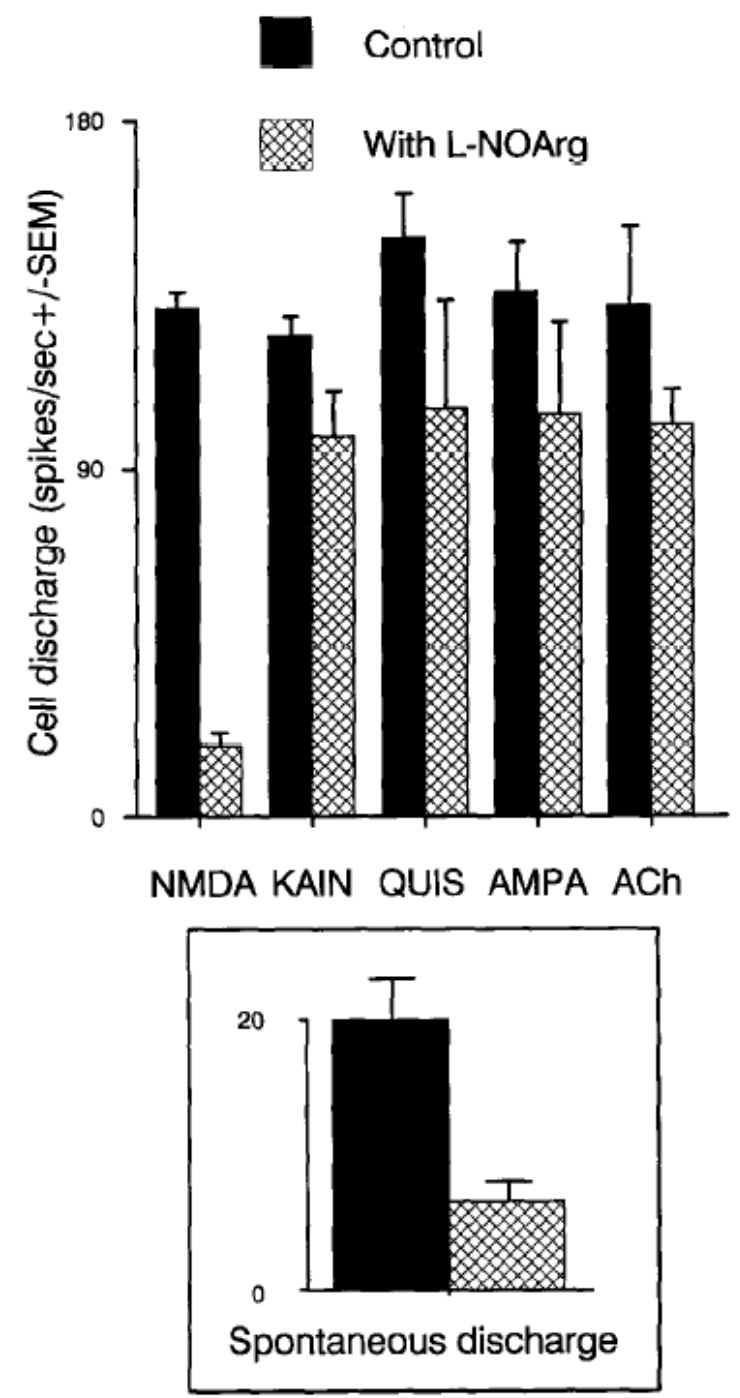

Fig. 3. Histogram comparing the responses of dLGN cells to a range of excitatory compounds before (solid bars) and during application of L-NOArg ( $80 \mathrm{nA}$, hatched bars). Iontophoretic doses producing approximately similar degrees of excitation were compared on a population of 12 cells, and results are given as mean number of spikes/set \pm SEM. Bottom figure: spontaneous activity of the same cells before and during application of L-NOArg-note the change in scale of the y-axis. 


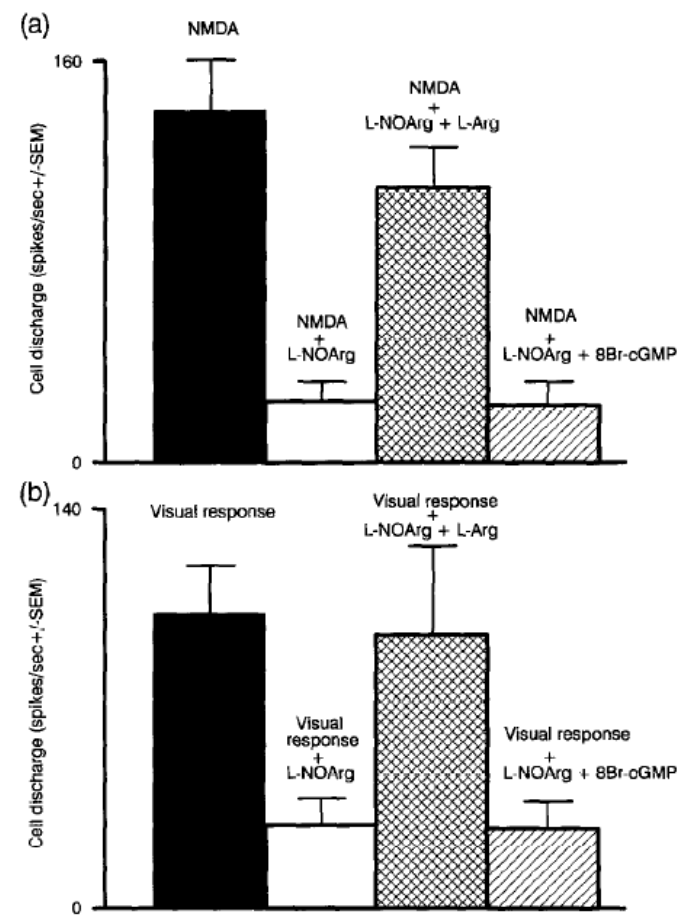

Fig. 4. (a) Histogram documenting the mean responses of a population of $10 \mathrm{dLGN}$ cells to NMDA alone, NMDA + LNOArg, NMDA + L-NOArg + L-Arg and NMDA + LNOArg + 8-bromo-cGMP (left to right: NMDA, 90 nA; L-NOArg and L-Arg, 80 nA; S-bromo-cGMP, $80 \mathrm{nA}$ ). Increased 8-bromo-cGMP currents to $120 \mathrm{nA}$ were similarly without effect (data not shown). (b) Similar histogram to (a) in this case substituting the NMDA driven discharge for a visually elicited excitatory response. The visual response was produced by a spot of light of optimum diameter flashed over the receptive field centre. Responses are mean f SEM.

\section{Discussion}

We have shown, both here and in previously published work (Cudeiro et al., 1994a), that the nature of the visual stimulus, and by extension the synaptic pathway involved, is not critical for the action of NO we report. Instead, with the data presented above, the evidence favours the view that the normal action of $\mathrm{NO}$ in this system is permissive, allowing complete expression of NMDA-evoked excitation from whichever source. Interestingly previously published work, almost without exception, from other, nonsensory, neural systems, has localized NOS within the post-synaptic cell bodies, suggesting that at least one mode of action is upon pre-synaptic elements, acting by diffusion to alter levels of transmitter release (Garthwaite, 1991).

The previous hypotheses regarding the mode of action and physiological role of NO have been exclusively based upon this anatomical localization. However, the NOS system within the cat dLGN, we believe, is so far unique. Here NOS is exclusively localized within presynaptic axonal terminals, not cell somata; in fact only within the terminals of axons arising from cholinergic cells with somata located within the parabrachial region of the brainstem (Bickford et al., 1993). Thus the possibility exists of a novel system of N.9 action at this locus. The actions we have outlined above are significantly different from many of the previously held views of NO function at the cellular level (Arnold et al., 1977; Miki et al., 1977; Deguchi and Yoshioka, 1982; Garthwaite et al., 1988, 1989; Bredt and Snyder, 1989; Manzoni and Bockaert, 1993; Tanaka et al., 1993). Simply put, previous evidence has favoured two possible modes of action for NO. Firstly, an action mediated by increased production of presynaptic cGMP thereby increasing excitatory transmitter release and, by extension as we have shown above, increasing post-synaptic cell activity [but supporting a role in NMDA mediated neurotoxicity (see Dawson et al., 1991, 1993)]. However, within the cat dLGN we have been unable to alter the effect of blockade of NO production using a cGMP analogue, and are therefore reluctant to accept that here at least this mechanism is in operation. Secondly, it has been suggested that NO may act directly upon the NMDA receptor (Aizenman et al., 1989; Lei et al., 1992; Lipton et al., 1993) to alter the configuration of the molecule, and thereby to decrease the effectiveness of endogenous and, of course exogenous agonists of NMDA receptors, implying a neuroprotective function. 
Our data cannot directly address this issue, since the neuroprotective actions outlined are not activated in our in vivo experimental design, which utilizes only normal physiological or pharmacological, rather than pathological, mechanisms. In isolated in vitro slices of sensory CNS, Pape and Mager (1992) have suggested one further mode of action, in which NO modulates the activity of the post-synaptic cation current $I_{h}$ resulting in a shift from the burst mode of firing associated with sleep to the tonic mode associated with arousal. Once more, this is certainly not a mechanism easily amenable to study within our anaesthetized in vivo preparation. Instead, our results with application of NMDA clearly suggests a more fundamental action, also post-synaptic, by which the normal function of the presynaptic location of NOS gates or permits complete expression of the retinal input to dLGN relay cells, via NMDA receptors. Obviously, the location of the enzyme in the dLGN, within presynaptic axonal terminals, suggests a very specific physiological role, related in function to that of the cholinergic action with which it shares an anatomical location. Acetylcholine is released from presynaptic terminals in response to incoming action potentials, the rate of which are considered to be related to the level of arousal (Singer, 1977; Sherman and Koch, 1986; Steriade and Llinas, 1988). It therefore seems likely that release of NO, produced in a calcium-dependent manner, may follow such synaptic drive, as presynaptic calcium levels alter. Rising levels of NO may then affect post-synaptic cell mechanisms both by the action we have described upon NMDA receptors, or an action on $I_{h}$ (Pape and Mager, 1992). Although we have no direct evidence for such hypotheses, it is pertinent to note that in our hands application of L-Arg alone is without effect, suggesting that the available NOS is unable to utilize increased levels of substrate, perhaps requiring increased intracellular $\mathrm{Ca}^{2+}$ for higher production. To address this issue directly, we must attempt to apply $\mathrm{NO}$, or an analogue of $\mathrm{NO}$, to dLGN cells directly, work which is currently in progress in our laboratory.

To conclude, we believe our data supports the view that within the dLGN, the NO system represents an essentially continually active, but possibly modifiable, system for the gating of NMDA mediated excitation; required for normal physiological visual function, but with a role in neuropathology not excluded.

Acknowledgements: Supported by grants from XUGA, DGICYT and Fundacion Rich, Spain.

\section{References}

Aizenman E., Lipton S. A. and Loring R. H. (1989) Selective modulation of NMDA responses by reduction and oxidation. Neuron 2: 1257-1263.

Arnold W. P., Mittal C. K., Katsuki S. and Murad F. (1977) Nitric oxide activates guanylate cyclase and increases guanosine 3':5'-cyclic monophosphate levels in various tissue preparations. Proc. Natn. Acad. Sci. U.S.A. 74: 3203-3207.

Bickford M. E., Giinhik A. E., Guido W. and Sherman S. M. (1993) Evidence that cholinergic axons from the parabrachial region of the brainstem are the exclusive source of nitric oxide in the lateral geniculate nucleus of the cat. J. Comp. Neurol. 334: 410-430.

Bohme G. A., Bon C., Stutzmann J.-M., Doble A. and Blanchard J.-C. (1991) Possible involvement of nitric oxide in long-term potentiation. Eur. J. Pharmac. 199: 379-381.

Bredt D. S. and Snyder S. H. (1989) Nitric oxide mediates glutamated-linked enhancement of cGMP levels in the cerebellum. Proc. Natn. Acad. Sci. U.S.A. 86: 9030-9033.

Cudeiro J., Rivadulla C., Rodríguez R., Martínez-Conde S., Acuña C. and Alonso J. M. (1994a) Modulatory influence of putative inhibitors of nitric oxide synthesis on visual processing in the cat lateral geniculate nucleus. J. Neurophysiol. 71: 146-149.

Cudeiro J., Rodríguez R., Rivadulla C.. Martinez-Conde S., Acuña C. and Alonso J. M. (1994b) Nitric oxide modulates the transfer of information at the level of the cat visual thalamus acting on postsynaptic NMDA receptors. Plügers Arch. (Supp)) 427: R50.

Dawson V. L., Dawson T. M., London E. D., Bredt D. S. and Snyder S. H. (1991) Nitric oxide mediates glutamate neurotoxicity in primary cortical cultures. Proc. Natn. Acad. Sci. U.S.A. 88: 6368-6371.

Dawson V. L., Dawson T. M., Bartley D. A., Uhl G. R. and Snyder S. H. (1993) Mechanisms of nitric oxidemediated neurotoxicity in primary, brain cultures. J. Neurosci. 13: 2651-2661.

Deguchi T. and Yoshioka K. (1982) L-Arginine identified as an endogenous activator for soluble guanylate cyclase from neuroblastoma cells. J. Biol. Chem. 257: 10147-10151.

Garthwaite J. (1991) Glutamate, nitric oxide and cell-cell signalling in the nervous system. Trends Neurosci. 14: 6067.

Garthwaite J., Charles S. L. and Chess-Williams R. (1988) Endothelium-derived relaxing factor release on activation of NMDA receptors suggests role as intercellular messenger in the brain. Nature 336: 385-388.

Garthwaite J., Garthwaite G., Palmer R. M. J. and Moncada S. (1989) NMDA receptor activation induces nitric oxide synthesis from arginine in rat brain slices. Eur. J. Pharmac. 172: 413-416. 
Haley J. E., Wilcox G. L. and Chapman P. F. (1992) The role of nitric oxide in hippocampal long-term potentiation. Neuron 8: 211-216.

Izumi Y., Clifford D. B. and Zorumsky C. F. (1992) Inhibition of long-term potentiation by NMDA-mediated nitric oxide release. Science 257: 1273-1276.

Kemp J. A. and Sillito A. M. (1982) The nature of the excitatory transmitter mediating X and Y cell inputs to the cat dorsal lateral geniculate nucleus. J. Physiol. Land. 323: 377.391.

Klatt P., Schmidt K., Brunner F. and Mayer B. (1994) Inhibitors of brain nitric oxide synthase. Proc. Natn. Acad. Sci. U.S.A. 269: 1674-1680.

Lei S. Z., Pan Z.-H., Aggarwal S. K., Chen H.-S. V., Hartman J., Sucher N. J. and Lipton S. A. (1992) Effect of nitric oxide production on the redox modulatory site of the NMDA receptor-channel complex. Neuron 8: 1087-1099.

Lipton S. A., Choi Y.-B., Pan Z.-H., Lei S. Z., Chen H.-S. V., Sucher N. J., Loscalzo J., Singel D. J. \& Stamler J. S. (1993) A redox-based mechanism for the neuroprotective and neurodestructive effects of nitric oxide and related nitrosocompounds. Nature 364: 626-632.

Manzoni 0. and Bockaert J. (1993) Nitric oxide synthase activity endogenously modulates NMDA receptors. $J$. Neurochem. 61: 368-370.

Miki N., Kawabe Y. and Kuriyama K. (1977) Activation of cerebral guanylate cyclase by nitric oxide. Biochem. Biophys. Res. Commun. 75: 851-856.

Moncada S., Palmer R. M. J. and Higgs E. A. (1991) Nitric oxide: physiology, pathophysiology, and pharmacology. Pharmac. Reu. 43: 109-142.

Pape H. C. and Mager R. (1992) Nitric oxide controls oscillatory activity in thalamocortical neurons. Neuron 9: 441448.

Schuman E. M. and Madison D. V. (1991) A requirement for the intercellular messenger nitric oxide in long-term potentiation. Science 254: 1503-1 506

Sherman S. M. and Koch C. (1986) The control of retinogeniculate transmission in the mammalian lateral geniculate nucleus. Expl. Brain Res. 63: 1-20.

Shibuki K. and Okada D. (1991) Endogenous nitric oxide release required for long-term synaptic depression in the cerebellum. Nature 349: 326-328.

Sillito A. M. (1992) GABA mediated inhibitory processes in the function of the geniculo-striate system. Progress in Brain Research, 90, 349-384.

Sillito A. M., Cudeiro J. and Murphy P. C. (1993) Orientation sensitive elements in the corticofugal influence on centresurround interactions in the dorsal lateral geniculate nucleus. Expl. Brain Res. 93: 6-16.

Sillito A. M., Murphy P. C., Salt T. E. and Moody C. I. (1990) The dependence of retinogeniculate transmission in the cat on NMDA receptors. J. Neurophysiol. 63: 347-355.

Singer W. (1977) Control of thalamic transmission by corticofugal and ascending reticular pathways in the visual system. Physiol. Rec. 57: 386-420.

Snyder S. H. and Bredt D. S. (1991) Nitric oxide as a neuronal messenger. Trends Pharmac. Sci. 12: 125-128.

Steriade M. and Llinas R. R. (1988) The functional states of the thalamus and the associated neuronal interplay. Physiol. Rev. 68: 6499742. Tanaka T., Saito H. and Matsuki N. (1993) Endogenous nitric oxide inhibits NMDAand kainate-responses by a negative feedback system in at hippocampal neurons. Brain Res. 631: 72-76. 